\title{
Protein Flexibility of the $a$-Ketoglutarate-Dependent Oxygenase Factor-Inhibiting HIF-1: Implications for Substrate Binding, Catalysis, and Regulation
}

\author{
Cristina B. Martin ${ }^{\dagger}$, Vanessa D. Chaplin ${ }^{\dagger}$, Stephen J. Eyles ${ }^{\ddagger}$, Michael J. Knapp ${ }^{\star}, \dagger$ \\ tDepartment of Chemistry, University of Massachusetts, Amherst, Massachusetts 01003, United \\ States \\ FDepartment of Biochemistry and Molecular Biology, University of Massachusetts, Amherst, \\ Massachusetts 01003, United States
}

\section{Abstract}

Protein dynamics are crucial for the mechanistically ordered enzymes to bind to their substrate in the correct sequence and perform catalysis. Factor-inhibiting HIF-1 (FIH) is a nonheme Fe(II) $a$ ketoglutarate-dependent oxygenase that is a key hypoxia (low $p_{\mathrm{O}_{2}}$ ) sensor in humans. As these hypoxia-sensing enzymes follow a multistep chemical mechanism consuming $a$-ketoglutarate, a protein substrate that is hydroxylated, and $\mathrm{O}_{2}$, understanding protein flexibility and the order of substrate binding may aid in the development of strategies for selective targeting. The primary substrate of FIH is the C-terminal transactivation domain (CTAD) of hypoxia-inducible factor $1 a$ (HIF) that is hydroxylated on the side chain of Asn803. We assessed changes in protein flexibility connected to metal and $a \mathrm{KG}$ binding, finding that $(\mathrm{M}+a \mathrm{KG})$ binding significantly stabilized the cupin barrel core of FIH as evidenced by enhanced thermal stability and decreased protein dynamics as assessed by global amide hydrogen/deuterium exchange mass spectrometry and limited proteolysis. Confirming predictions of the consensus mechanism, $(\mathrm{M}+a \mathrm{KG})$ increased the affinity of FIH for CTAD as measured by titrations monitoring intrinsic tryptophan fluorescence. The decreased protein dynamics caused by $(\mathrm{M}+a \mathrm{KG})$ enforces a sequentially ordered substrate binding sequence in which $a \mathrm{KG}$ binds before CTAD, suggesting that selective inhibition may require inhibitors that target the binding sites of both $a \mathrm{KG}$ and the prime substrate. A consequence of the correlation between dynamics and $a \mathrm{KG}$ binding is that all relevant ligands must be included in binding-based inhibitor screens, as shown by testing permutations of $\mathrm{M}, a \mathrm{KG}$, and inhibitor.

\section{Graphical Abstract}

\footnotetext{
*Corresponding Author: mknapp@ chem.umass.edu. Phone: (413) 545-4001. Fax: (413) 545-4490.

The authors declare no competing financial interest.

Supporting Information

The Supporting Information is available free of charge on the ACS Publications website at DOI:10.1021/acs.biochem.9b00619. CTAD binding titration of (Mn+aKG)FIH, CD spectra of FIH bound to $a \mathrm{KG}$, and $T_{\mathrm{M}}$ values for FIH with different ligands (PDF)

Accession Codes

FIH, Q9NWT6.
} 


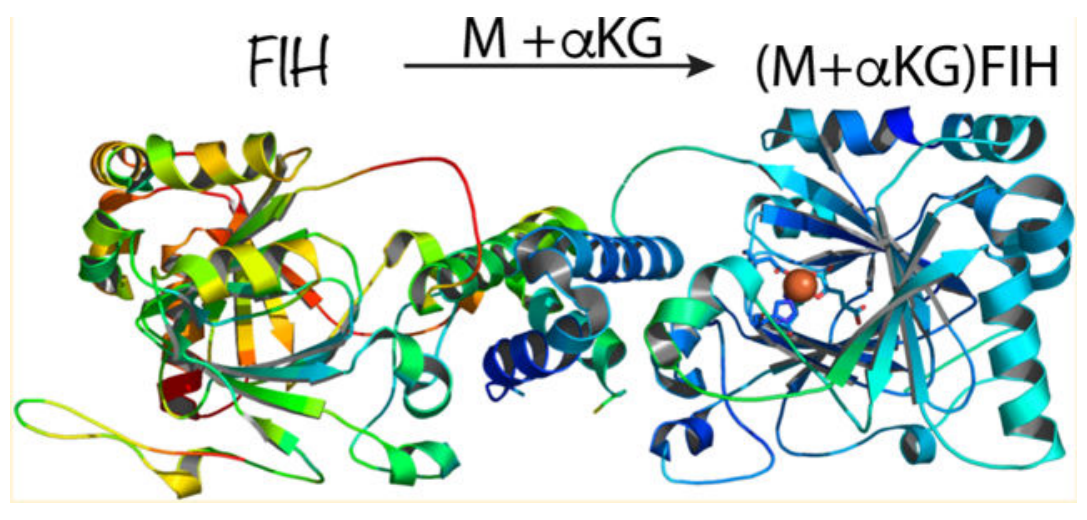

Protein dynamics play a key role in slow time scale events involved in ligand and substrate binding and have been shown to couple to active site chemistry. ${ }^{1,2}$ The functional significance of these dynamics should be particularly high for enzymes with multisubstrate reactions and those involved in modifying other proteins. Hypoxia (low $p_{\mathrm{O}_{2}}$ ) sensing is a

rich area for such interesting enzymes, as it is typified by complex protein/protein recognitions and covalent modifications. ${ }^{3}$ The nexus in eukaryotic hypoxia sensing is hypoxia-inducible factor $1 a$ (HIF-1 $a$ ), which is regulated by several enzymes, including factor-inhibiting HIF (FIH; UniProt entry Q9NWT6). ${ }^{4,5}$ FIH is a nonheme Fe(II) $a$ ketoglutarate-dependent oxygenase that senses $p_{\mathrm{O}_{2}}$ in humans by hydroxylating Asn803 in the C-terminal transactivation domain (CTAD) of HIF-1 $a$, transcriptionally repressing HIF-1 under normal $p_{\mathrm{O}_{2}}{ }^{5,6}$ Due to the variety of reactions catalyzed by $a$ KG-dependent oxygenases,${ }^{7}$ their conserved protein fold, ${ }^{8}$ and the use of protein substrates, ${ }^{9}$ dynamics may play a significant role in determining the substrate binding order and active site chemistry for FIH and related enzymes.

Structures of FIH bound to varied substrates and cofactor reveal that the equilibrium structure of FIH does not change when binding varied transition metals $(\mathrm{M}=\mathrm{Fe}$ or $\mathrm{Zn})$, $a \mathrm{KG}, \mathrm{CTAD}, \mathrm{NO}$ as a mimic of $\mathrm{O}_{2},{ }^{10}$ or some combination thereof. ${ }^{11-13}$ The use of a nonnative metal permits structural studies while avoiding deleterious autoxidation reactions. In contrast, average $B$-factors in the refined structures show that thermal fluctuations of FIH decrease upon binding $(\mathrm{M}+a \mathrm{KG}),{ }^{11,12}$ and a mechanistic study further revealed that the access of $\mathrm{O}_{2}$ to the active site was not limited by constriction in a narrow channel. ${ }^{14}$ These kinetic and structural data suggest that protein dynamics may be essential for ligand binding in FIH, as seen for ligand binding in other metalloenzymes. ${ }^{15-17}$ Establishing the connection between protein dynamics and substrate binding may provide insight into the sequential chemical mechanism as well as providing hints for selectively targeting members of this important enzyme superfamily. 7,18

The consensus reaction mechanism for this family of nonheme iron aKG-dependent oxygenases is based on the HAG mechanism, ${ }^{19}$ which assumes that $a \mathrm{KG}$ is the first substrate to bind. ${ }^{20,21} \mathrm{Next}$, the prime substrate binds near the cofactor, triggering the subsequent reaction with $\mathrm{O}_{2}$ and leading to tightly coupled hydroxylation. ${ }^{22-25}$ Research on 
$\mathrm{FIH}^{24,26,27}$ and other $a \mathrm{KG}$ oxygenases indicates that triggering is due, at least in part, to the prime substrate causing the release of an aquo ligand from the $\mathrm{Fe}$ (II) to open a binding site for $\mathrm{O}_{2} \cdot{ }^{20,26-28}$ Although the body of evidence supporting a local change in coordination at $\mathrm{Fe}(\mathrm{II})$ as a determining factor for $\mathrm{O}_{2}$ binding is growing, very few data concerning the order of substrate binding for $a \mathrm{KG}$ and the prime substrate exist.

X-ray crystallography identified three regions of FIH involved in CTAD binding. ${ }^{11}$ Site I binds to an extended conformation of CTAD 795-801; residues within the cupin barrel of FIH contact residues in the $\gamma$-turn from CTAD 802-805, containing the Asn803 target residue (Figure 1); and site II on FIH binding to a helical stretch of CTAD 812-823. Truncated forms of CTAD consisting of residues 788-806 serve as substrates, albeit with a much weaker affinity $\left(K_{\mathrm{M}}=400 \mu \mathrm{M}\right),{ }^{29}$ indicating that site I and the target residue site are essential for the binding of CTAD to FIH. This leads to important predictions for CTAD binding.

First, the multiple points of contact between Asn803 and the Fe/aKG center suggest that the affinity for CTAD will depend on the Fe coordination environment. When FIH was first identified as a protein that interacts with HIF-1 from yeast two-hybrid assays, it was noted that the short CTAD peptides (HIF-1 a 786-826) did not bind FIH under the GST pull-down assay conditions, ${ }^{31}$ but similar short peptides (HIF-1 a 788-826) were satisfactory standalone substrates under turnover conditions. ${ }^{32}$ These structural and biochemical observations suggested that the affinity for CTAD would increase in the presence of $(\mathrm{M}+a \mathrm{KG})$.

Second, the constrained conformation of the $\gamma$-turn suggests that protein dynamics are coupled to CTAD binding and may impact the positioning of the CTAD Asn803 target residue. The substrate binding order for FIH can be viewed as a matter of the extent to which $a \mathrm{KG}$ binding leads to a tighter affinity for CTAD. Although the crystal structures for the apo $^{12}$ and $(\mathrm{M}+a \mathrm{KG}) \mathrm{FIH}$ and $(\mathrm{M}+a \mathrm{KG}) \mathrm{FIH} / \mathrm{CTAD}$ enzyme forms ${ }^{11,13}$ showed a very small deviation in atomic positions [root-mean-square deviation of $1.38 \AA$ for Protein Data Bank (PDB) entries $1 \mathrm{IZ3}$ and $1 \mathrm{H} 2 \mathrm{~K}]$, analysis of the experimental $B$-factors revealed that binding $(\mathrm{Fe}+a \mathrm{KG})$ decreased the flexibility of the outer rims of the cupin barrel core consisting of $a$-helices and loops. ${ }^{11,12}$ This reduced protein flexibility for the (Fe+aKG)FIH enzyme form suggested that the CTAD binding site would be stabilized by coordination of $a \mathrm{KG}$ to $\mathrm{Fe}(\mathrm{II})$.

Here, we show that binding of $(\mathrm{M}+a \mathrm{KG})$ to FIH decreases protein flexibility and increases the affinity for CTAD, indicating that sequential substrate binding is the result of an induced fit process caused by protein dynamics. We used the non-native metal Mn to avoid autoxidation reactions that can occur with the native Fe. This establishes changes in protein dynamics essential for the sequentially ordered mechanism of FIH, raising the potential that dynamics in other $a$ KG-dependent oxygenases may be functionally significant. ${ }^{16,33}$ Decreased protein dynamics in FIH upon binding $(\mathrm{M}+a \mathrm{KG})$ reveal metal is required for binding-based inhibitor screens, as shown by a thermal stability assay of the binding of the inhibitor to FIH. The correlation between $(\mathrm{M}+a \mathrm{KG})$ binding and protein dynamics has important ramifications on the nature of substrate binding, catalysis, and the design and screening of selective inhibitors for FIH. 


\section{MATERIALS AND METHODS}

\section{Materials.}

All reagents were purchased from commercial vendors and were used as received, with the exception of the 39-residue CTAD peptide substrate that was obtained from EZBiolab (Carmel, IN) as a desalted product. The CTAD sequence that was used corresponded to that of human HIF-1 a 788-826, with the exception of a C800A variation to prevent disulfide formation: (Asn803 underlined) DESGLPQLTSYDAEVNAPIQGSRNLLQGEELLRALDQVN with unmodified termini. The peptide was purified prior to use by reverse phase high-performance liquid chromatography (RP-HPLC) to at least 95\% purity. The concentration of the peptide was determined by monitoring the absorbance of the Tyr residue at $293 \mathrm{~nm}\left(\varepsilon=2400 \mathrm{M}^{-1} \mathrm{~cm}^{-1}\right)$ in $0.1 \mathrm{M}$ $\mathrm{NaOH} \cdot{ }^{34}$

\section{FIH Expression and Purification.}

BL21-DE3 Escherichia coli cells containing the wild-type FIH/pET28a plasmid were grown in $2 \mathrm{X}$ YT media $(25 \mathrm{~g} / \mathrm{L})$ supplemented with $30 \mu \mathrm{g} / \mathrm{mL}$ kanamycin at $37{ }^{\circ} \mathrm{C}$ with constant shaking. The cells were induced with $0.5 \mathrm{mM}$ isopropyl $\beta$-D-1-thiogalactopyranoside (IPTG) and harvested by centrifugation. Cell lysis was facilitated by lysozyme $(1 \mathrm{mg} / \mathrm{mL})$ and sonication on ice for $30 \mathrm{~min}$. The crude cell lysate was repeatedly dialyzed against $10 \mathrm{mM}$ Tris ( $\mathrm{pH}$ 8.0) at $4{ }^{\circ} \mathrm{C}$. Purification of the His-tagged enzyme was carried out by Ni-affinity chromatography using a peristaltic pump system (Bio-Rad). The His tag attached to the Nterminus was then removed by incubation with thrombin ( $0.5 \mathrm{unit} / \mathrm{mg}$ of protein) for $36 \mathrm{~h}$ at $4{ }^{\circ} \mathrm{C}$. Further overnight incubation with $50 \mathrm{mM}$ EDTA (pH 8.0) at $4{ }^{\circ} \mathrm{C}$ was performed for metal removal. The protein sample was loaded onto a Sephadex G75 resin column to obtain the FIH dimer. The purity of the enzyme was checked by SDS-PAGE. The concentration of the protein was estimated by ultraviolet (UV) absorbance at $280 \mathrm{~nm}$ using an $\varepsilon_{280}$ of 1.22 $\mathrm{mL} \mathrm{mg}{ }^{-1} \mathrm{~cm}^{-1}$.34

\section{Ligand Binding by Intrinsic Fluorescence Quenching.}

The samples in the cuvette for fluorescence experiments contained the following components as indicated: $2 \mu \mathrm{M} \mathrm{FIH}, 50 \mu \mathrm{M} \mathrm{MnSO}_{4}, 500 \mu \mathrm{M} a \mathrm{KG}$, and $200 \mu \mathrm{M} \mathrm{HIF-1a/}$ CTAD in $50 \mathrm{mM}$ HEPES (pH 7.00) with $100 \mathrm{mM} \mathrm{NaCl}$. All samples were mixed thoroughly and then incubated at room temperature $\left(23^{\circ} \mathrm{C}\right)$ for at least 3 min prior to the measurement of fluorescence with a Photon Technology International Quantamaster-4 SE fluorimeter. The tryptophan fluorescence emission scan was done in the wavelength range of 300-375 nm using excitation and emission slit widths of 0.1 and $2.5 \mathrm{~mm}$, respectively. The excitation wavelength used was $295 \mathrm{~nm}$, and the emission intensity at $330 \mathrm{~nm}$ was monitored.

For binding experiments, the samples were prepared without the HIF-1 a/CTAD substrate. The titrant solution contained $2.8 \mathrm{mM}$ HIF- 1 a/CTAD, $2 \mu \mathrm{M} \mathrm{FIH,} 50 \mu \mathrm{M} \mathrm{MnSO}_{4}$, and 500 $\mu \mathrm{M} a \mathrm{KG}$ in $50 \mathrm{mM}$ HEPES ( $\mathrm{pH}$ 7.0) with the total ionic strength maintained at $100 \mathrm{mM}$ using $\mathrm{NaCl}$. The generated emission spectra were baseline-corrected with the buffer blank and smoothed using the adjacent averaging method in OriginPro. The titration data were 
obtained by recording the magnitude of the emission intensity at $330 \mathrm{~nm}$. The binding data were fitted to a Langmuir binding equation

$$
Y=\frac{Y_{\max }[\mathrm{L}]}{K+[\mathrm{L}]}
$$

where $Y_{\max }$ is normalized to unity and $K$ is the binding affinity.

\section{Thermal Stability Experiments.}

Protein samples for the thermal melt curve experiments contained one or two or all of the following components: $5 \mu \mathrm{M}$ FIH, $50 \mu \mathrm{M} \mathrm{MnSO}_{4}$, and $500 \mu \mathrm{M} a \mathrm{KG}$ in $50 \mathrm{mM}$ HEPES (pH 7.0). For each sample, $45 \mu \mathrm{L}$ of the master mix was distributed in each well of the 96-well quantitative polymerase chain reaction microplate and $5 \mu \mathrm{L}$ of freshly prepared $5 \times$ SYPRO Orange (Sigma-Aldrich, 5000 $\times$ stock diluted in dimethyl sulfoxide) was thoroughly mixed into it. Inhibitor screens used similar conditions, with the exception of $5 \mu \mathrm{M} \mathrm{MnSO}_{4}$ and the addition of $100 \mu \mathrm{M}$ inhibitor. The microplate was sealed with a Microseal adhesive film, briefly spun, and immediately loaded onto a Bio-Rad CFX Connect RT-PCR machine, and the samples were heated at a rate of $1{ }^{\circ} \mathrm{C} / \mathrm{min}$ from 20 to $90{ }^{\circ} \mathrm{C}$. The fluorescence intensity (excitation wavelength range of 450-490 nm, emission wavelength range of 560-580 nm) was monitored as a function of temperature. The $T_{\mathrm{m}}$ was determined using the positive firstderivative plot of the data points generated. All thermal shift assay curves were fit to the Boltzmann equation from zero to maximum intensity to determine $T_{\mathrm{m}}$.

$$
y=\frac{A_{1}-A_{2}}{1+\mathrm{e}^{\left(x-x_{0}\right) / \mathrm{d} x}}+A_{2}
$$

\section{Global Hydrogen/Deuterium Exchange with Mass Spectrometry.}

For the HDX-MS experiments, a portable ice box equipped with an injection port and a C4 RP-HPLC column was used. It was connected to the HPLC pump on one end and the Turbo Ion Spray source of a QStarXL (AB Sciex, Framingham, MA) ESI-TOF mass spectrometer on the other end. All samples were initially prepared on ice prior to incubation at room temperature $\left(26^{\circ} \mathrm{C}\right)$. Samples contained $20 \mu \mathrm{M}$ FIH and one, two, or all of the following components upon final dilution into ammonium acetate buffer: $50 \mu \mathrm{M} \mathrm{MnSO}_{4}, 500 \mu \mathrm{M}$ $a \mathrm{KG}$, and $200 \mu \mathrm{M}$ CTAD in $50 \mathrm{mM}$ HEPES (pH 7.0) with the total ionic strength maintained at $100 \mathrm{mM}$ with $\mathrm{NaCl}$. A master mix for each of the different samples was initially prepared, from which a $2 \mu \mathrm{L}$ aliquot for each time point was incubated for $3 \mathrm{~min}$ at room temperature. Ammonium acetate buffer $(10 \mathrm{mM})$ in $\mathrm{H}_{2} \mathrm{O}(\mathrm{pH} 7.1)$ (for the $m_{0}$ control) or in $\mathrm{D}_{2} \mathrm{O}$ (pD 7.4) was then added to a final volume of $20 \mu \mathrm{L}$ to initiate $\mathrm{H} / \mathrm{D}$ exchange. Samples were quenched at varying time points by injection into the LC lines that had been equilibrated with $0.1 \%$ formic acid and kept on ice. A short gradient of $0.1 \%$ aqueous formic acid $/ 0.1 \%$ formic acid in acetonitrile was immediately initiated through the column at a constant flow rate of $200 \mu \mathrm{L} / \mathrm{min}$ with eluent for the first $3 \mathrm{~min}$ being directed to waste to avoid salt contamination of the ion source. The LC line was then connected to the mass 
spectrometer, and ESI-MS data were acquired in positive mode over a mass range of $\mathrm{m} / \mathrm{z}$ 200-2000. In total, 10 exchange time points were acquired from $25 \mathrm{~s}$ to $90 \mathrm{~min}$.

To account for the back-exchange during data acquisition, a nondeuterated control $\left(m_{0}\right)$ and a fully deuterated control $\left(m_{100}\right)$ were obtained. The fully deuterated control was prepared by incubation of the protein in $\mathrm{D}_{2} \mathrm{O}$ at $37^{\circ} \mathrm{C}$ for $16 \mathrm{~h}$ and then for $5 \mathrm{~min}$ at $90{ }^{\circ} \mathrm{C}$ prior to injection. The relative deuterium uptake $(D)$ was calculated using the equation ${ }^{35}$

$$
D=\frac{m_{\mathrm{obs}}-m_{0}}{m_{100}-m_{0}}
$$

The data points were fit to a triexponential equation where $y_{0}$ is the actual number of exchangeable amide protons under a given condition $(\% \mathrm{D}$ multiplied by $N$, where $N$ is the theoretical number of exchangeable amide protons; $N$ is the total number of amino acid residues - the number of Pro residues - 1 for the amino terminus; for FIH, $N=324$ ), and A$\mathrm{C}$ correspond to the slow, medium, and fast exchangers with assigned average rate constants of $k_{1}\left(0.05 \mathrm{~min}^{-1}\right), k_{2}\left(1 \mathrm{~min}^{-1}\right)$, and $k_{3}\left(20 \mathrm{~min}^{-1}\right)$, respectively:

$$
y=y_{0}-A \mathrm{e}^{-k_{1} t}-B \mathrm{e}^{-k_{2} t}-\mathrm{Ce}^{-k_{3} t}
$$

\section{Limited Proteolysis with Mass Spectrometry.}

Proteolysis experiments were carried out at $37.0^{\circ} \mathrm{C}$ with $150 \mu \mathrm{g}$ of FIH in $50 \mathrm{mM}$ Tris (pH 7.5) in the presence or absence of $100 \mu \mathrm{M} \mathrm{MnSO}_{4}$ and $500 \mu \mathrm{M} a \mathrm{KG}$. Samples were initially incubated on ice for $10 \mathrm{~min}$ and then at $37.0^{\circ} \mathrm{C}$ for $1 \mathrm{~min}$ prior to the addition of $0.5 \mathrm{mg} / \mathrm{mL}$ trypsin to a protease:substrate weight ratio of 1:300. Aliquots $(9 \mu \mathrm{L})$ were quenched at varying time points into $1 \mu \mathrm{L}$ of $10 \mathrm{mM}$ AEBSF and stored at $-80^{\circ} \mathrm{C}$ until use. The samples were analyzed as soon as possible. For SDS-PAGE analysis in a $12 \%$ acrylamide gel, $1.5 \mu \mathrm{L}$ of the quenched sample was mixed with $6 \mu \mathrm{L}$ of $2 \times$ gel loading buffer and diluted to a total volume of $10 \mu \mathrm{L}$ with $50 \mathrm{mM}$ Tris (pH 7.5). For MALDI-MS analysis, $3 \mu \mathrm{L}$ of the quenched sample was mixed with $15 \mu \mathrm{L}$ of $10 \mathrm{mg} / \mathrm{mL}$ sinapinic acid in $70 \% \mathrm{CH}_{3} \mathrm{CN} / 0.03 \%$ TFA and spotted onto a MALDI target for analysis. MALDI-TOF mass spectra of the limited proteolysis products were recorded over an $\mathrm{m} / \mathrm{z}$ range from 10000 to 60000 . To verify the protein terminal sequence via MALDI-ISD (in-source decay), the samples were mixed in a $1: 1$ ratio with $10 \mathrm{mg} / \mathrm{mL}$ sinapinic acid in $30 \% \mathrm{CH}_{3} \mathrm{CN} / 0.1 \%$ TFA. The air-dried spotted samples were briefly rinsed with cold water to remove excess salt and then air-dried again before analysis. MS/MS data were acquired in linear mode over a $\mathrm{m} / \mathrm{z}$ range from 300 to 20000 with a Bruker (Billerica, MA) MicroFlex LRF MALDI-TOF instrument using at least $50 \%$ laser power to induce ISD.

\section{Circular Dichroism Spectroscopy.}

Protein samples for circular dichroism (CD) measurements were prepared in $10 \mathrm{mM}$ $\mathrm{KH}_{2} \mathrm{PO}_{4}$ (pH 7.04) with $500 \mu \mathrm{M} a \mathrm{KG}$ and $50 \mu \mathrm{M} \mathrm{MnSO}_{4}$. Protein concentrations ranged from 0.2 to $0.4 \mathrm{mg} \mathrm{mL}^{-1}$ as measured by UV absorbance at $280 \mathrm{~nm}\left(\varepsilon_{280}=1.22 \mathrm{~mL} \mathrm{mg}^{-1}\right.$ $\mathrm{cm}^{-1}$ ). The spectra were recorded over the wavelength range of $190-250 \mathrm{~nm}$ at $37.0{ }^{\circ} \mathrm{C}$ 
using a highly transparent quartz cell with a path length of $0.1 \mathrm{~cm}$ on a Jasco J-1500 CD spectropolarimeter. The instrument was blanked with the buffer solution containing all constituents except the protein. All measurements were taken at least three times to ensure that the signal is for that of a sample at equilibrium. The averages of these measurements were used to generate the $\mathrm{CD}$ spectra.

\section{RESULTS AND DISCUSSION}

\section{Effect of $a K G$ on CTAD Affinity.}

The consensus mechanism for FIH and other $a \mathrm{KG}$ hydroxylases assumes sequential substrate binding in the following order: $a \mathrm{KG}$, prime substrate, and then $\mathrm{O}_{2}$. While this makes sense from the perspective of the chemistry, it is hard to reconcile an obligate sequential order based on the crystallographic structures of FIH bound to various substrates. Early reports of FIH/CTAD binding in biological assays suggested that $(\mathrm{M}+a \mathrm{KG})$ increased the binding affinity of FIH for the HIF-1 $a /$ CTAD domain. ${ }^{31}$ However, protein crystallography indicated that the equilibrium structure of FIH did not change upon binding $a \mathrm{KG}^{10,11}$ and that the CTAD binding site was invariant in the structures.

To directly test the effect of $a \mathrm{KG}$ on the CTAD binding affinity, we monitored the binding of CTAD to FIH via changes in the intrinsic tryptophan fluorescence intensity in the presence and absence of $a \mathrm{KG}$. Titration of $\$ 500 \mu \mathrm{M}$ CTAD into apoFIH did not lead to a lower-intensity fluorescence signal, even in the presence of $50 \mu \mathrm{M} \mathrm{Mn}^{2+}$, indicating a very weak affinity for CTAD $\left(\mathrm{K}_{\mathrm{D}}>1 \mathrm{mM}\right)$. In contrast, titration of $\$ 500 \mu \mathrm{M}$ CTAD into (Mn $+a \mathrm{KG}) \mathrm{FIH}$ led to a smooth decrease in Trp fluorescence, indicating moderate affinity for CTAD. Nonlinear curve fitting of the data for $(\mathrm{Mn}+a \mathrm{KG}) \mathrm{FIH}$ gave a $\mathrm{K}_{\mathrm{D}}$ of $92 \pm 9 \mu \mathrm{M}$, which is similar to the $\mathrm{K}_{\mathrm{M}}$ value $(\sim 90 \mu \mathrm{M})$ for FIH previously observed, ${ }^{34}$ indicating that $a \mathrm{KG}$ was essential for medium-affinity binding of CTAD to FIH. Notably, the $\mathrm{K}_{\mathrm{D}}$ for binding of CTAD to $(\mathrm{M}+a \mathrm{KG}) \mathrm{FIH}$ using varied metals $\left(\mathrm{M}=\mathrm{Mn}^{2+}\right.$ or $\left.\mathrm{Co}^{2+}\right)$ closely corresponded to the Michaelis constant for CTAD $\left(K_{\mathrm{M}} \sim 90 \mu \mathrm{M}\right)$, while the native metal (M $=\mathrm{Fe}^{2+}$ ) was used, confirming that the FIH protein structure is well ordered with the middle transition metals. This is consistent with the biophysical data using a variety of metals in the active site, including $\mathrm{Fe}, \mathrm{Co}$, and $\mathrm{Zn}$.

The FIH/CTAD affinity increased $>10$-fold in the presence of $a \mathrm{KG}$, indicating sequential binding of $a \mathrm{KG}$ followed by CTAD as assumed by the consensus mechanism. The origin of the increased affinity is unclear, as the FIH protein structure does not change upon binding $a \mathrm{KG}$. This suggests that altered protein dynamics of FIH may impact the CTAD binding site (Figure 2).

\section{Effect of $a K G$ on Metal Binding.}

Control titrations were performed to ensure full loading of the metal site of FIH. The isosteric $\mathrm{Mn}^{2+}$ was used in place of $\mathrm{Fe}^{2+}$ for binding assays to prevent complications due to autohydroxylation ${ }^{36}$ or enzyme turnover. Titration of citrate-buffered $\mathrm{Mn}^{2+}$ into FIH containing $500 \mu \mathrm{M} a \mathrm{KG}$ led to a monotonic decrease in the intrinsic tryptophan fluorescence of FIH, indicating the binding of metal to the active site. The normalized 
fluorescence was fit to a dose-response equation, with a $\mathrm{K}_{\mathrm{D}}$ of 13(2) $\mu \mathrm{M}$ for the equilibrium $\mathrm{FIH}(\mathrm{Mn}+a \mathrm{KG}) \rightleftharpoons \mathrm{FIH}+a \mathrm{KG}+\mathrm{Mn}^{2+}$. The binding affinity for $\mathrm{Mn}^{2+}$ is very similar to that for $\mathrm{Co}^{2+}[14(1) \mu \mathrm{M}],{ }^{37}$ which has been shown to be a good substitute for $\mathrm{Fe}^{2+} .{ }^{34} \mathrm{~A}$ similar titration in which $a \mathrm{KG}$ was omitted did not lead to a change in fluorescence, indicating that high-affinity binding of metal to the FIH active site required $a \mathrm{KG}$.

\section{Effect of M+aKG Binding on FIH Structure and Stability.}

Although protein crystallography showed that the protein backbone structure of apoFIH could be superimposed upon that of $(\mathrm{M}+a \mathrm{KG}) \mathrm{FIH},{ }^{11}$ this reflects the equilibrium structure without revealing protein flexibility or dynamics and may be perturbed by crystal packing forces. To test for changes in the secondary structures of FIH upon $(\mathrm{M}+a \mathrm{KG})$ binding, $\mathrm{CD}$ spectra of the apo and (Mn+aKG)-bound enzyme forms were obtained. Each spectrum had two negative features around 210 and $219 \mathrm{~nm}$ and a positive feature at $191 \mathrm{~nm}$, indicating a mixed $a$-helix $/ \beta$-strand structure. The similarity of each spectrum showed that the secondary structure of FIH in solution was not significantly impacted by binding $(\mathrm{Mn}+a \mathrm{KG})$, supporting the retention of structure seen by crystallography.

The thermal stability of FIH was measured to test for stability changes upon cofactor and substrate binding (Figure 3). Addition of $\mathrm{Mn}^{2+}$ along with $a \mathrm{KG}$ increased the apparent melting temperature from 47 to $52{ }^{\circ} \mathrm{C}$. This $5{ }^{\circ} \mathrm{C}$ increase in the enzyme's thermal stability was consistent with $(\mathrm{Mn}+a \mathrm{KG})$ addition leading to a more tightly folded structure of the protein; a similar observation of the stabilizing effect of $a \mathrm{KG}$ was also seen for the other HIF hydroxylase, PHD2. ${ }^{38,39}$ Addition of only $\mathrm{Mn}^{2+}$ to FIH did not stabilize the protein $\left(T_{\mathrm{M}}\right.$ $=47^{\circ} \mathrm{C}$ ), consistent with the very weak binding of $\mathrm{Mn}^{2+}$ by FIH in the absence of $a \mathrm{KG}$.

\section{Impact of (Mn+aKG) on Global Amide Exchange (HDX-MS).}

As $a \mathrm{KG}$ binding did not alter the average protein structure, the increase in protein stability suggested that FIH became less dynamic upon binding M+aKG. Comparing the $B$-factors for apoFIH (PDB entry $1 \mathrm{IZ}^{12}$ ) and $(\mathrm{M}+a \mathrm{KG}) \mathrm{FIH}\left(\mathrm{PDB}\right.$ entry $\left.1 \mathrm{H} 2 \mathrm{~N}^{11}\right)$ structures revealed a global decrease in these refinement parameters upon binding $(\mathrm{M}+a \mathrm{KG})$, suggesting that backbone dynamics also decreased. As HIF-1 a/CTAD is unstructured in solution, ${ }^{40} \mathrm{a}$ preformed CTAD binding site on FIH would serve to select the correct conformation of the CTAD domain. We assessed the flexibility of the FIH protein via global amide H/D exchange experiments coupled to mass spectrometry (HDX-MS) (Figure 4). Global HDX measures the isotopic exchange of ${ }^{1} \mathrm{H}$ in backbone amide $\mathrm{N}-\mathrm{H}$ protons with ${ }^{2} \mathrm{H}$ in solvent $\mathrm{D}_{2} \mathrm{O}$, leading to an increase in mass upon forming the amide $\mathrm{N}-\mathrm{D}$. For tightly folded proteins, amide HDX occurs via the transient unfolding of local protein structure, such that amide HDX measures backbone dynamics over the time scale of seconds to hours. Both kinetics and the number of amides undergoing amide HDX are observed, leading to an overall view of protein flexibility in solution.

Global amide HDX was measured for FIH over $100 \mathrm{~min}$, in which the increase in mass was fit to eq 3 (Table 1) to account for amides exchanging over a wide time scale. The varied parameters were the numbers of exchanging amides, as the three rate constants were fixed to reduce variables by binning amides into three different exchange time scales. ApoFIH 
exhibited $>50 \%$ D uptake, with a broad distribution between slow $(\mathrm{A}=47)$, medium $(\mathrm{B}=$ $55)$, and fast $(\mathrm{C}=84)$ exchanging amides. The overall amide exchange distribution was similar for the FIH sample containing $\mathrm{Mn}^{2+}$, which was expected as $\mathrm{Mn}^{2+}$ did not bind to FIH in the absence of $a \mathrm{KG}$. In contrast, the (Mn+aKG)FIH sample achieved <50\% D uptake over the time scale of measurement, indicating a more rigid protein structure. The distribution of amide exchangers for (Mn+aKG)FIH further differed from that of apoFIH in the significant decrease in the number of fast $(C=51)$ exchanging amides, again indicating that the overall protein became much more rigid upon binding $a \mathrm{KG}$. A similar observation using the same global amide HDX method was also noted in our lab for the other HIF hydroxylase, PHD2. ${ }^{39}$

The decreased flexibility of FIH upon binding $a \mathrm{KG}$ suggested that broad segments of FIH become less dynamic once bound to $a \mathrm{KG}$. This experimental result is also consistent with a molecular dynamics study ${ }^{41}$ that predicted substantially reduced flexibility for FIH in the presence of $a \mathrm{KG}$. When considered along with the decrease in the crystallographic $B$ factors upon binding $\mathrm{Fe}+a \mathrm{KG},{ }^{11,12}$ these results indicate a reduction in protein dynamics for FIH once $a \mathrm{KG}$ binds to the active site.

\section{Limited Proteolysis: MALDI-TOF MS in Parallel with SDS-PAGE Analysis.}

To gain better local insight into the decreased flexibility of $(\mathrm{Mn}+a \mathrm{KG}) \mathrm{FIH}$, limited proteolysis was performed. Limited proteolysis is widely used for studies of protein dynamics as it relies on transient unfolding to expose proteolytic cleavage sites. Ligand binding can cause regions of the protein to change in conformation and become less solvent accessible, which can lead to a decreased rate of proteolytic cleavage. ${ }^{38}$ We used trypsin due to its high specificity for Arg/Lys residues, which facilitates downstream identification of the generated proteolytic fragments, giving structural information about the protein regions that were stabilized upon $a \mathrm{KG}$ binding.

FIH is a homodimeric protein that dissociates under denaturing conditions to run as a single band at $41 \mathrm{kDa}$ via SDS-PAGE. The SDS-PAGE of trypsinolysis products of apoFIH (Figure 5) revealed that the intact protein (band 1, 41 kDa) was successively cleaved into three heavy fragments, the lightest of which (band 4, $\sim 34 \mathrm{kDa}$ ) appeared to diminish in abundance at long time points presumably due to cleavage into smaller tryptic peptides. A similar pattern of fragmentation was observed for $(\mathrm{Mn}+a \mathrm{KG}) \mathrm{FIH}$, but with two notable differences from the pattern for apoFIH. First, full-length $(\mathrm{Mn}+a \mathrm{KG}) \mathrm{FIH}$ was not cleaved as rapidly as apoFIH, as shown by the higher relative abundance of intact protein after digestion for $15 \mathrm{~min}$ (Figure 5B). Second, the $34 \mathrm{kDa}$ band (band 4) accumulated for (Mn $+a \mathrm{KG}) \mathrm{FIH}$ out to $240 \mathrm{~min}$, whereas this band was visibly reduced from the apoFIH lanes (Figure 5A); an even greater difference was noted at $1440 \mathrm{~min}$ (Figure 5C).

The intensity of band 4 remained strong even after proteolytic treatment in $(\mathrm{Mn}+a \mathrm{KG}) \mathrm{FIH}$ for $24 \mathrm{~h}$, whereas it completely disappeared for the apoenzyme under this longer incubation period (Figure 5C). This points to the $34 \mathrm{kDa}$ fragment as corresponding to a stable core of FIH in the presence of Mn and $a \mathrm{KG}$. Collectively, limited proteolysis, melting temperatures, and global amide HDX data indicated that $a \mathrm{KG}$ binding leads to a less dynamic and more 
tightly structured protein core in $(\mathrm{Mn}+a \mathrm{KG}) \mathrm{FIH}$, which agreed with the predictions from molecular dynamics. ${ }^{41}$

Limited proteolysis samples were analyzed using MALDI-TOF mass spectrometry to identify the $34 \mathrm{kDa}$ stabilized core. The MALDI data revealed the presence of proteolytic fragments with $m / Z$ values that were in excellent agreement with the bands observed by SDS-PAGE and could further be compared to the tryptic cleavage pattern predicted for FIH (Figure 6). The protein sequence of FIH (Figure 7) illustrated the three predicted cleavage sites at residues with high solvent accessibility. While sequential trypsin cleavage from either terminus of FIH could lead to similar pattern fragments, attention was focused on those Lys/Arg residues at the $\mathrm{N}$-terminus because the FIH homodimer interface is at the Cterminus. Monomeric FIH is unstable, suggesting that residues found at the dimer interface are unlikely to be accessible for proteolysis, a suggestion supported by the MALDI data (see below).

The three trypsin sites at the N-terminus of FIH are Arg17, Arg44, and Arg51. Successive trypsin cleavage of the protein at these sites would generate fragments as follows (Table 2): cleavage of the intact protein at Arg17 (39 kDa fragment), cleavage at Arg44 ( $\sim 36 \mathrm{kDa}$ fragment), and cleavage at Arg51 ( $34 \mathrm{kDa}$ fragment). Importantly, each cleavage would result in a truncated protein with an intact cupin barrel for $a \mathrm{KG}$ binding.

Band 4 ( $\sim 34 \mathrm{kDa}$ fragment) was tentatively assigned as the cupin barrel core due to the observed stability of this fragment to trypsinolysis. Sequencing data were obtained via ISD using MALDI-TOF mass spectrometry (Figure 8) to positively identify this band. MALDIISD is a useful tool for top-down sequencing to verify the end termini of intact known proteins. ${ }^{42}$ The fragmentation process during ISD occurs via a radical pathway, so the major fragment ions expected are the $c_{n}$ and $\left(z_{n}+2\right)$ ions. ${ }^{43}$ Peaks corresponding to the ladder of $\left(z_{n}+2\right)$ ions as well as some $\mathrm{c}$ ions generated at $60 \%$ laser power were observed and identified for the parallel sample [(Mn+aKG)FIH] quenched after trypsin incubation for $4 \mathrm{~h}$. This particular sample was chosen due to the accumulation of the $\sim 34 \mathrm{kDa}$ fragment (Figures 5 and 6). A few $y$ ions were also observed, which are less common than the $c_{n}$ and $z_{n}$ ions but further support the assigment. ${ }^{42,43}$ This analysis verified the $\mathrm{N}$-terminal sequence of the fragment by virtue of the ladder of $\mathrm{c}$ ions, which indicated that Arg51 was the Nterminal residue. Similarly, the residues involved in FIH dimerization were also identified from the $z$ ion ladder, indicating that the residues up through Asn349 were present in the $~ 34$ $\mathrm{kDa}$ fragment (Table 3). This confirms that the stable enzyme core observed by SDS-PAGE as band 4 corresponds to FIH51-FIH349, the cupin barrel along with the dimerization interface.

MALDI-ISD sequencing showed that the $34 \mathrm{kDa}$ stabilized core of $(\mathrm{Mn}+a \mathrm{KG}) \mathrm{FIH}$ includes the cupin barrel and the dimerization interface, as well as the entire CTAD binding site (Figure 9). Upon binding $a \mathrm{KG}$, FIH adopts a more rigid structure as shown by the lower extent of amide HDX and susceptibility to proteolysis induced by $a \mathrm{KG}$. The stabilizing effect of $a \mathrm{KG}$ on FIH reflects the coordinate bonds formed to the metal cofactor, the salt bridges formed to $a \mathrm{KG}$, and the numerous second-sphere contacts that serve to connect metal ligands to the $\beta$-strands across the cupin barrel. As it is common to find a similar 
pattern of the hydrogen bonding within the cupin barrel, ${ }^{8}$ it is likely that many other $a \mathrm{KG}$ hydroxylases will be similarly stabilized by $a \mathrm{KG}$ binding.

\section{Screening Inhibitors by a Thermal Shift Assay.}

FIH is the subject of inhibition studies as it regulates key physiological processes related to proliferation. These studies have led to many successes, as reviewed previously; ${ }^{18}$ however, a challenge with identifying new inhibitors for FIH is that the activity assays are not easily amenable to high-throughput screening methods. ${ }^{18} \mathrm{~A}$ general thermal shift assay was described in 2004 for ligand binding to proteins, based on the change in fluorescence from a dye that is sensitive to protein denaturation. ${ }^{44}$ Binding of a ligand to protein will stabilize the protein and lead to a shift in the melting temperature. In this assay, the thermocycler function on an RT-PCR instrument was used to vary the melting temperature while SYPRO Orange dye provided the fluorescent signal, suggesting that such an assay might work to detect ligand binding to FIH.

FIH was screened against $N$-oxalylglycine (NOG), a ligand that is known to bind to the enzyme at the $a \mathrm{KG}$ site. ${ }^{11} \mathrm{In}$ view of the cooperative binding of $\mathrm{M}^{2+}$ along with $a \mathrm{KG}$, we tested different combinations of the ligand and metal for their ability to shift the melting temperature ( $\left.T_{\mathrm{M}}\right)$ of FIH. The addition of $\mathrm{Mn}^{2+}$ or $a \mathrm{KG}$ to FIH did not increase $T_{\mathrm{M}}\left(T_{\mathrm{M}}=\right.$ 52.9-53.0), consistent with the results from intrinsic fluorescence quenching (Figure 2) and amide HDX (Figure 4), showing that $\mathrm{Mn}^{2+}$ did not bind to FIH. In contrast, the $\mathrm{T}_{\mathrm{M}}$ increased significantly when $\mathrm{Mn}^{2+}$ was added in the presence of $100 \mu \mathrm{M} a \mathrm{KG}$ (55.3) or NOG (57.1), indicating that these ligands bound cooperatively with $\mathrm{Mn}^{2+}$ to stabilize FIH from unfolding (Figure 10).

The thermal shift results lead to two important outcomes. First, a fluorometric thermal stability assay can be used to detect ligand binding to FIH. This assay should be amenable to high-throughput screens of compound libraries for FIH inhibitors, provided users observe the synergy between metal and $a \mathrm{KG}$ binding sites. Second, in concert with the amide HDX and proteolysis results, $(\mathrm{Mn}+a \mathrm{KG})$ binding leads to a decrease in protein dynamics, stabilizing FIH from denaturation.

\section{Implications for Catalysis.}

Binding $(\mathrm{M}+a \mathrm{KG})$ causes FIH to adopt a less flexible structure, providing a structural basis for the sequentially ordered mechanism of FIH. Upon binding (M+aKG), the CTAD binding site shifts from low affinity $\left(K_{\mathrm{D}}>1 \mathrm{mM}\right)$ to moderate affinity $\left(K_{\mathrm{D}}=80 \mu \mathrm{M}\right)$, leading to a rigorously sequential binding order. ${ }^{24}$ This has a practical effect, as there is but a narrow solvent accessible channel to the active site in the FIH/CTAD adduct, ${ }^{14}$ which would prevent $a \mathrm{KG}$ from entering the active site were CTAD present. Otherwise, one could envision that CTAD binding to apoFIH might inhibit turnover by blocking $a \mathrm{KG}$ from reaching the active site.

The contrast between binding of HIF-1 $a$ to FIH and PHD2 is striking, despite the fact that these enzymes bind peptides from the respective domains of HIF- $1 a$ in constrained orientations. ${ }^{11,45}$ Although both enzymes become less dynamic once bound to $(\mathrm{M}+a \mathrm{KG})$, the $\beta 2-\beta 3$ loop of PHD remains dynamic even when the oxygen-dependent degradation 
domain (ODDD) is bound. ${ }^{38}$ While this work shows that FIH requires $(\mathrm{M}+a \mathrm{KG})$ to bind to the HIF-CTAD domain, PHD2 binds HIF-ODDD in the absence of added (M+aKG). ${ }^{46,47}$ This difference may arise due to the more buried active site in PHD2, which is closed from the solvent once the $\beta 2-\beta 3$ loop closes onto the ODDD domain, in contrast to the more open active site of FIH, which is closed from the solvent only by the CTAD domain itself. In both examples, prime substrate binding limits the access of the solvent to the cofactor, which sets the stage for the chemical steps leading to hydroxylation.

This has important ramifications for catalysis by FIH and other aKG-dependent hydroxylases. The stabilizing effect of $(\mathrm{M}+a \mathrm{KG})$ binding on FIH both reduces protein flexibility and ensures sequential substrate binding, which demonstrates that global protein flexibility is an effective strategy for enforcing ordered chemistry. When we discuss enzyme/ substrate binding, it is common to think in terms of concepts related to small substrates binding within large active sites, such as the lock-and-key or the induced fit models that can destabilize the substrate for subsequent reaction. These concepts are inexact for FIH/CTAD, due to the large protein/peptide interface that would involve a large decrease in entropy upon binding from conformational entropy, solvent entropy, and translational entropy. The decreased dynamics of the $(\mathrm{M}+a \mathrm{KG}) \mathrm{FIH}$ enzyme form would help to alleviate some of this entropic cost associated with binding CTAD. In this sense, while FIH/CTAD can be viewed as an induced fit binding, this is largely a matter of overcoming the entropic penalty inherent to organizing three reactants $\left(a \mathrm{KG}, \mathrm{CTAD}\right.$, and $\left.\mathrm{O}_{2}\right)$ in the correct orientation and proximity for reaction.

The flexibility of the CTAD binding site also suggests that FIH inhibition may require targeting of the $a \mathrm{KG}$ binding site rather than the CTAD binding site, or at least ensuring that $a \mathrm{KG}$ be filled. As the buried $a \mathrm{KG}$ site is more attractive for small molecule inhibitors than a protein/peptide interface, the general approach for FIH inhibitors has been to target the $a \mathrm{KG}$ initially. ${ }^{18}$ However, targeting the $a \mathrm{KG}$ binding site leads to challenges due to the potential for bidentate chelators to bind metals in solution leading to metal sequestration, as well as due to the wide array of enzymes using $a \mathrm{KG}$ as a substrate. These challenges are similar to those faced in targeting other metalloproteins ${ }^{48}$ and are not insurmountable. For example, generic inhibitor templates for several $a$ KG-dependent hydroxylases have been identified, ${ }^{18}$ leading to a degree of selectivity for several of the enzymes. In the case of FIH, selective inhibition may be best achieved by targeting both the $a \mathrm{KG}$ and CTAD binding site simultaneously, ${ }^{18}$ as reported for a family of $N$-oxalyl amino acids selective for FIH over PHD2. ${ }^{49}$

\section{Supplementary Material}

Refer to Web version on PubMed Central for supplementary material.

\section{ACKNOWLEDGMENTS}

The authors thank Prof. Richard Vachet for the use of the PTI Quantamaster-4 SE fluorimeter and Prof. Michelle Farkas for the use of the Bio-Rad CFX Connect Real-Time PCR Detection System. Mass spectral data were obtained at the University of Massachusetts Mass Spectrometry Core Facility.

Funding 
This research was supported by National Institutes of Health Grant 1R01-GM077413 to M.J.K.

\section{ABBREVIATIONS}

$a \mathrm{KG}$

CTAD

EDTA

ESI-TOF MS

FIH

GST

HDX-MS

HEPES

HIF

MALDI-TOF MS

MW

NOG

SDS-PAGE

TFA $a$-ketoglutarate

C-terminal transactivation domain

ethylenediaminetetraacetic acid

electrospray ionization/time-of-flight mass spectrometry

factor-inhibiting HIF-1

glutathione $S$-transferase

hydrogen/deuterium exchange mass spectrometry

4-(2-hydroxyethyl)-1-piperazineethanesulfonic acid

hypoxia-inducible factor $1 a$

matrix-assisted laser desorption ionization/time-of-flight

mass spectrometry

molecular weight

$N$-oxalylglycine

sodium dodecyl sulfate-polyacrylamide gel electrophoresis

trifluoroacetic acid

\section{REFERENCES}

(1). Klinman JP, and Kohen A (2014) Evolutionary aspects of enzyme dynamics. J. Biol. Chem 289, 30205-30212. [PubMed: 25210031]

(2). Vaughn MB, Zhang J, Spiro TG, Dyer RB, and Klinman JP (2018) Activity-Related Microsecond Dynamics Revealed by Temperature-Jump Forster Resonance Energy Transfer Measurements on Thermophilic Alcohol Dehydrogenase. J. Am. Chem. Soc 140, 900-903. [PubMed: 29323490]

(3). Chaplin VD, Barbato AN, and Knapp MJ (2018) Mammalian O2 Sensing and Signalling. In Gas Sensing in Cells (Aono S, Ed.) pp 219-252, Royal Society of Chemistry.

(4). Bruick RK, and McKnight SL (2001) A conserved family of prolyl-4-hydroxylases that modify HIF. Science 294, 1337-1340. [PubMed: 11598268]

(5). Lando D, Peet DJ, Gorman JJ, Whelan DA, Whitelaw ML, and Bruick RK (2002) FIH-1 is an asparaginyl hydroxylase enzyme that regulates the transcriptional activity of hypoxia-inducible factor. Genes Dev. 16, 1466-1471. [PubMed: 12080085]

(6). Hewitson KS, McNeill LA, Riordan MV, Tian YM, Bullock AN, Welford RW, Elkins JM, Oldham NJ, Bhattacharya S, Gleadle JM, Ratcliffe PJ, Pugh CW, and Schofield CJ (2002) Hypoxiainducible factor (HIF) asparagine hydroxylase is identical to factor inhibiting HIF (FIH) and is related to the cupin structural family. J. Biol. Chem 277, 26351-26355. [PubMed: 12042299]

(7). Hausinger RP (2004) FeII/alpha-ketoglutarate-dependent hydroxylases and related enzymes. Crit. Rev. Biochem. Mol. Biol 39, 21-68. [PubMed: 15121720] 
(8). Hangasky JA, Taabazuing CY, Valliere MA, and Knapp MJ (2013) Imposing function down a (cupin)-barrel: secondary structure and metal stereochemistry in the alpha KG-dependent oxygenases. Metallomics 5, 287-301. [PubMed: 23446356]

(9). Ozer A, and Bruick RK (2007) Non-heme dioxygenases: cellular sensors and regulators jelly rolled into one? Nat. Chem. Biol 3, 144-153. [PubMed: 17301803]

(10). Taabazuing CY, Fermann J, Garman S, and Knapp MJ (2016) Substrate Promotes Productive Gas Binding in the alpha-Ketoglutarate-Dependent Oxygenase FIH. Biochemistry 55, 277-286. [PubMed: 26727884]

(11). Elkins JM, Hewitson KS, McNeill LA, Seibel JF, Schlemminger I, Pugh CW, Ratcliffe PJ, and Schofield CJ (2003) Structure of factor-inhibiting hypoxia-inducible factor (HIF) reveals mechanism of oxidative modification of HIF-1 alpha. J. Biol. Chem 278, 1802-1806. [PubMed: 12446723]

(12). Lee C, Kim SJ, Jeong DG, Lee SM, and Ryu SE (2003) Structure of human FIH-1 reveals a unique active site pocket and interaction sites for HIF-1 and von Hippel-Lindau. J. Biol. Chem 278, 7558-7563. [PubMed: 12482756]

(13). Dann CE, Bruick RK, and Deisenhofer J (2002) Structure of factor-inhibiting hypoxia-inducible factor 1: An asparaginyl hydroxylase involved in the hypoxic response pathway. Proc. Natl. Acad. Sci. U. S. A 99, 15351-15356. [PubMed: 12432100]

(14). Chaplin VD, Valliere MA, Hangasky JA, and Knapp MJ (2018) Investigations on the role of a solvent tunnel in the alpha-ketoglutarate dependent oxygenase factor inhibiting HIF (FIH). J. Inorg. Biochem 178, 63-69. [PubMed: 29078149]

(15). Aitha M, Moller AJ, Sahu ID, Horitani M, Tierney DL, and Crowder MW (2016) Investigating the position of the hairpin loop in New Delhi metallo-beta-lactamase, NDM-1, during catalysis and inhibitor binding. J. Inorg. Biochem 156, 35-39. [PubMed: 26717260]

(16). Ergel B, Gill ML, Brown L, Yu BM, Palmer AG, and Hunt JF (2014) Protein Dynamics Control the Progression and Efficiency of the Catalytic Reaction Cycle of the Escherichia coli DNARepair Enzyme AlkB. J. Biol. Chem 289, 29584-29601. [PubMed: 25043760]

(17). Poppe L, Tegley CM, Li V, Lewis J, Zondlo J, Yang E, Kurzeja RJM, and Syed R (2009) Different Modes of Inhibitor Binding to Prolyl Hydroxylase by Combined Use of X-ray Crystallography and NMR Spectroscopy of Paramagnetic Complexes. J. Am. Chem. Soc 131, 16654-16655. [PubMed: 19886658]

(18). Rose NR, McDonough MA, King ONF, Kawamura A, and Schofield CJ (2011) Inhibition of 2oxoglutarate dependent oxygenases. Chem. Soc. Rev 40, 4364-4397. [PubMed: 21390379]

(19). Hanauske-Abel HM, and Gunzler V (1982) A stereo-chemical concept for the catalytic mechanism of prolylhydroxylase: Applicability to classification and design of inhibitors. J. Theor. Biol 94, 421-455. [PubMed: 6281585]

(20). Pavel EG, Zhou J, Busby RW, Gunsior M, Townsend CA, and Solomon EI (1998) Circular dichroism and magnetic circular dichroism spectroscopic studies of the non-heme ferrous active site in clavaminate synthase and its interaction with alpha-ketoglutarate cosubstrate. J. Am. Chem. Soc 120, 743-753.

(21). Zhou J, Kelly WL, Bachmann BO, Gunsior M, Townsend CA, and Solomon EI (2001) Spectroscopic studies of substrate interactions with clavaminate synthase 2, a multifunctional alpha-KG-dependent non-heme iron enzyme: Correlation with mechanisms and reactivities. J. Am. Chem. Soc 123, 7388-7398. [PubMed: 11472170]

(22). Matthews ML, Krest CM, Barr EW, Vaillancourt FH, Walsh CT, Green MT, Krebs C, and Bollinger JM (2009) Substrate-Triggered Formation and Remarkable Stability of the C-H BondCleaving Chloroferryl Intermediate in the Aliphatic Halogenase, SyrB2. Biochemistry 48, 43314343. [PubMed: 19245217]

(23). McCusker KP, and Klinman JP (2009) Modular behavior of tauD provides insight into the origin of specificity in alpha-ketoglutarate-dependent nonheme iron oxygenases. Proc. Natl. Acad. Sci. U. S. A 106, 19791-19795. [PubMed: 19892731]

(24). Hangasky JA, Saban E, and Knapp MJ (2013) Inverse Solvent Isotope Effects Arising from Substrate Triggering in the Factor Inhibiting Hypoxia Inducible Factor. Biochemistry 52, 1594 1602. [PubMed: 23351038] 
(25). Grzyska PK, Ryle MJ, Monterosso GR, Liu J, Ballou DP, and Hausinger RP (2005) Steady-state and transient kinetic analyses of taurine/alpha-ketoglutarate dioxygenase: Effects of oxygen concentration, alternative sulfonates, and active-site variants on the fe(IV)-oxo intermediate. Biochemistry 44, 3845-3855. [PubMed: 15751960]

(26). Light KM, Hangasky JA, Knapp MJ, and Solomon EI (2013) Spectroscopic Studies of the Mononuclear Non-Heme Fe-II Enzyme FIH: Second-Sphere Contributions to Reactivity. J. Am. Chem. Soc 135, 9665-9674. [PubMed: 23742069]

(27). Light KM, Hangasky JA, Knapp MJ, and Solomon EI (2014) First- and second-sphere contributions to $\mathrm{Fe}(\mathrm{II})$ site activation by cosubstrate binding in non-heme Fe enzymes. Dalton Trans. 43, 1505-1508. [PubMed: 24292428]

(28). Zhou J, Gunsior M, Bachmann BO, Townsend CA, and Solomon EI (1998) Substrate Binding to the $a$-Ketoglutarate-Dependent Non-Heme Iron Enzyme Clavaminate Synthase 2: Coupling Mechanism of Oxidative Decarboxylation and Hydroxylation. J. Am. Chem. Soc 120, 1353913540 .

(29). Ehrismann D, Flashman E, Genn DN, Mathioudakis N, Hewitson KS, Ratcliffe PJ, and Schofield CJ (2007) Studies on the activity of the hypoxia-inducible-factor hydroxylases using an oxygen consumption assay. Biochem. J 401, 227-234. [PubMed: 16952279]

(30). DeLano WL (2002) The PyMOL Molecular Graphics System, version 2.0, Schrödinger, LLC.

(31). Mahon PC, Hirota K, and Semenza GL (2001) FIH-1: a novel protein that interacts with HIF-1 alpha and VHL to mediate repression of HIF-1 transcriptional activity. Genes Dev. 15, 26752686. [PubMed: 11641274]

(32). Koivunen P, Hirsila M, Gunzler V, Kivirikko KI, and Myllyharju J (2004) Catalytic properties of the asparaginyl hydroxylase $(\mathrm{FIH})$ in the oxygen sensing pathway are distinct from those of its prolyl 4-hydroxylases. J. Biol. Chem 279, 9899-9904. [PubMed: 14701857]

(33). Mbenza NM, Vadakkedath PG, McGillivray DJ, and Leung IKH (2017) NMR studies of the nonhaem Fe(II) and 2-oxoglutarate-dependent oxygenases. J. Inorg. Biochem 177, 384-394. [PubMed: 28893416]

(34). Chen YH, Comeaux LM, Herbst RW, Saban E, Kennedy DC, Maroney MJ, and Knapp MJ (2008) Coordination changes and auto-hydroxylation of FIH-1: uncoupled $\mathrm{O}_{2}$-activation in a human hypoxia sensor. J. Inorg. Biochem 102, 2120-2129. [PubMed: 18805587]

(35). Liu YH, and Konermann L (2006) Enzyme conformational dynamics during catalysis and in the 'resting state' monitored by hydrogen/deuterium exchange mass spectrometry. FEBS Lett. 580, 5137-5142. [PubMed: 16963025]

(36). Chen Y-H, Comeaux LM, Eyles SJ, and Knapp MJ (2008) Auto-hydroxylation of FIH-1, an $\mathrm{Fe}(\mathrm{II})$, a-ketoglutarate dependent human hypoxia sensor. Chem. Commun, 4768-4770.

(37). Saban E, Chen YH, Hangasky JA, Taabazuing CY, Holmes BE, and Knapp MJ (2011) The Second Coordination Sphere of FIH Controls Hydroxylation. Biochemistry 50, 4733-4740. [PubMed: 21456582]

(38). Stubbs CJ, Loenarz C, Mecinovic J, Yeoh KK, Hindley N, Lienard BM, Sobott F, Schofield CJ, and Flashman E (2009) Application of a Proteolysis/Mass Spectrometry Method for Investigating the Effects of Inhibitors on Hydroxylase Structure. J. Med. Chem 52, 2799-2805. [PubMed: 19364117]

(39). Pektas S, and Knapp MJ (2013) Substrate preference of the HIF-prolyl hydroxylase-2 (PHD2) and substrate-induced conformational change. J. Inorg. Biochem 126, 55-60. [PubMed: 23787140]

(40). Dames SA, Martinez-Yamout M, De Guzman RN, Dyson HJ, and Wright PE (2002) Structural basis for Hif-1 alpha/CBP recognition in the cellular hypoxic response. Proc. Natl. Acad. Sci. U. S. A 99, 5271-5276. [PubMed: 11959977]

(41). Park H, Ko S, and Jeon YH (2010) Force field design and molecular dynamics simulations of factor-inhibiting HIF-1 and its complex with known inhibitors: implications for rational inhibitor design. J. Mol. Graphics Modell 29, 221-228.

(42). Brown RS, and Lennon JJ (1995) Sequence-specific fragmentation of matrix-assisted laserdesorbed protein/peptide ions. Anal. Chem 67, 3990-3999. [PubMed: 8633762] 
(43). Suckau D, and Resemann A (2003) T3-sequencing: targeted characterization of the N- and Ctermini of undigested proteins by mass spectrometry. Anal. Chem 75, 5817-5824. [PubMed: 14588022]

(44). Lo MC, Aulabaugh A, Jin G, Cowling R, Bard J, Malamas M, and Ellestad G (2004) Evaluation of fluorescence-based thermal shift assays for hit identification in drug discovery. Anal. Biochem 332, 153-159. [PubMed: 15301960]

(45). Chowdhury R, McDonough MA, Mecinovic J, Loenarz C, Flashman E, Hewitson KS, Domene C, and Schofield CJ (2009) Structural Basis for Binding of Hypoxia-Inducible Factor to the Oxygen-Sensing Prolyl Hydroxylases. Structure 17, 981-989. [PubMed: 19604478]

(46). Flashman E, Bagg EAL, Chowdhury R, Mecinovic J, Loenarz C, McDonough MA, Hewitson KS, and Schofield CJ (2008) Kinetic rationale for selectivity toward N- and C-terminal oxygendependent degradation domain substrates mediated by a loop region of hypoxia-inducible factor prolyl hydroxylases. J. Biol. Chem 283, 3808-3815. [PubMed: 18063574]

(47). Abboud MI, McAllister TE, Leung IKH, Chowdhury R, Jorgensen C, Domene C, Mecinovic J, Lippl K, Hancock RL, Hopkinson RJ, Kawamura A, Claridge TDW, and Schofield CJ (2018) 2Oxoglutarate regulates binding of hydroxylated hypoxia-inducible factor to prolyl hydroxylase domain 2. Chem. Commun 54, 3130-3133.

(48). Rouffet M, and Cohen SM (2011) Emerging trends in metalloprotein inhibition. Dalton Trans. 40, 3445-3454. [PubMed: 21290034]

(49). McDonough MA, McNeill LA, Tilliet M, Papamicael CA, Chen QY, Banerji B, Hewitson KS, and Schofield CJ (2005) Selective inhibition of factor inhibiting hypoxia-inducible factor. J. Am. Chem. Soc 127, 7680-7681. [PubMed: 15913349] 


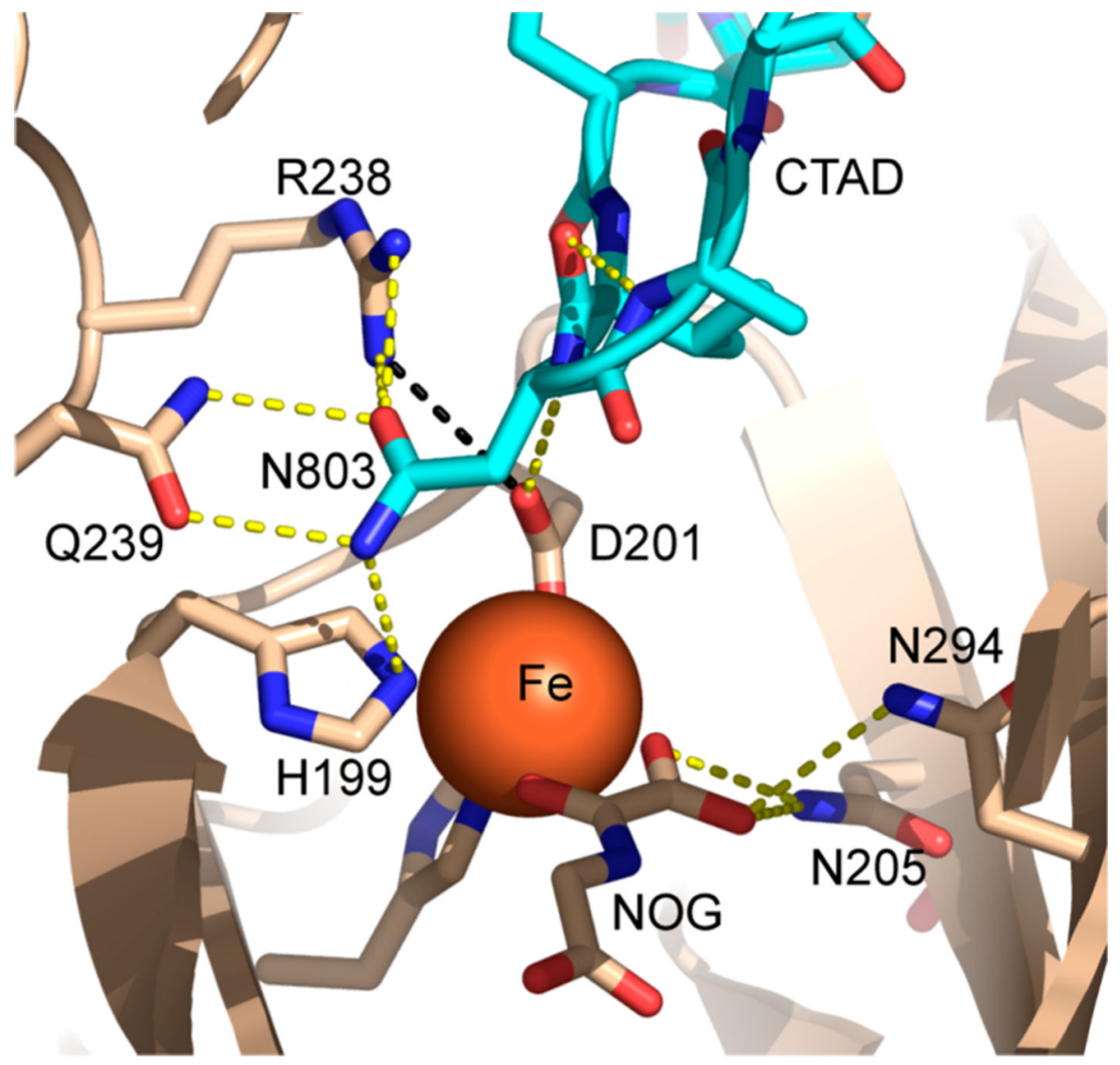

Figure 1.

Polar contacts between FIH (wheat) and CTAD (cyan) found in Protein Data Bank entry $1 \mathrm{H} 2 \mathrm{~K}^{11}$ imaged using PyMOL. ${ }^{30}$ Residue numbers are included for select residues, NOG ( $N$-oxalylglycine). 


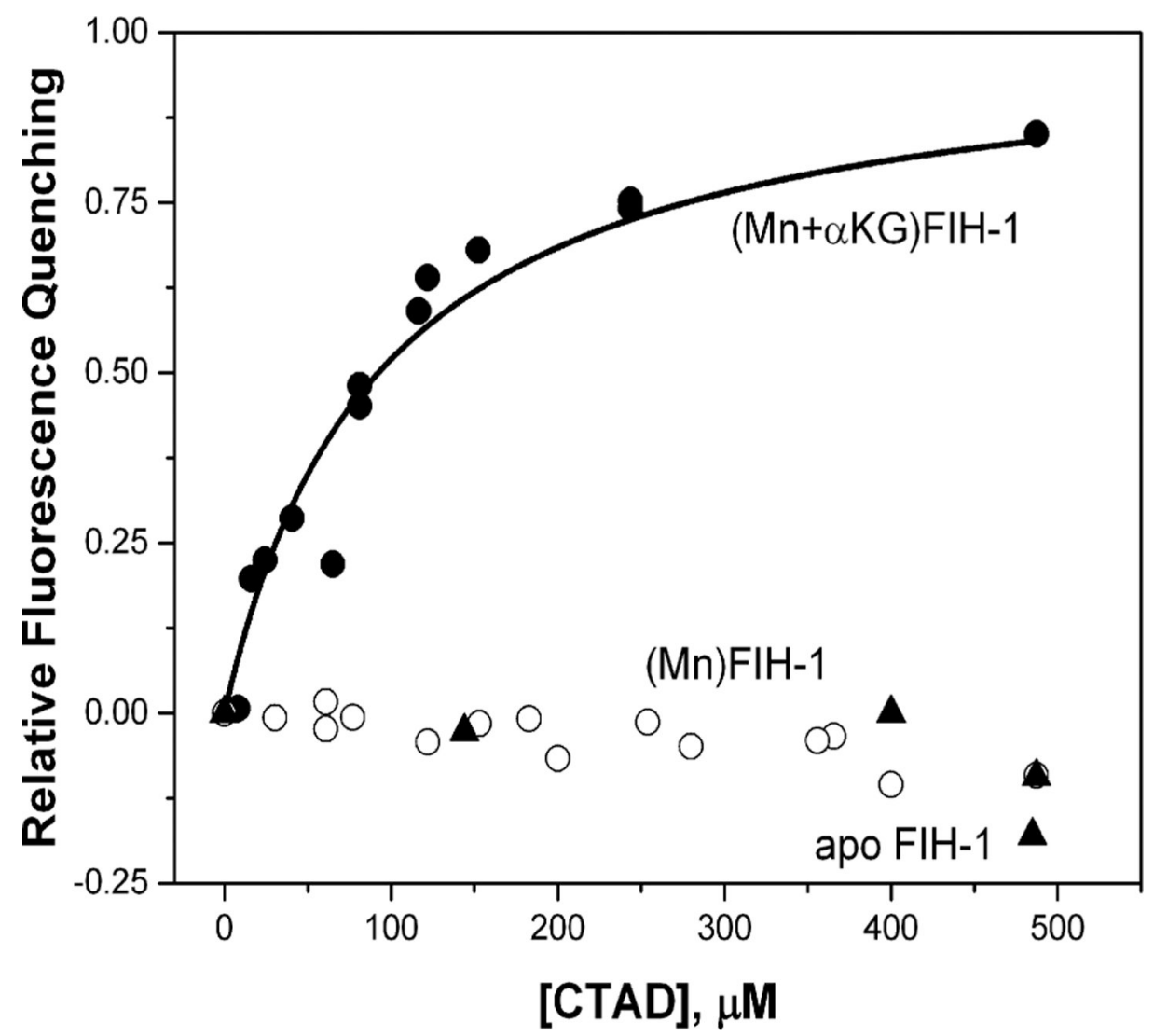

Figure 2.

Binding of HIF-1 a/CTAD substrate to FIH in the presence of $a \mathrm{KG}(\mathbf{O})$ and in the absence of $a \mathrm{KG}(\mathrm{O}$; apoFIH, $\mathbf{\Delta})$. Samples contained one, two, or all of the following components: 2 $\mu \mathrm{M}$ FIH, $50 \mu \mathrm{M} \mathrm{MnSO}_{4}$, and $500 \mu \mathrm{M} a \mathrm{KG}$ in $50 \mathrm{mM}$ HEPES (pH 7.00). The experiment was performed in duplicate at an excitation $\lambda$ of $295 \mathrm{~nm}$, and the intrinsic fluorescence quenching was monitored between 300 and $375 \mathrm{~nm}$. Nonlinear regression analysis of the plot for the $a \mathrm{KG}$-bound enzyme using eq 1 gave a $K_{\mathrm{D}}$ of $92 \pm 9 \mu \mathrm{M}$ (Figure 2). 


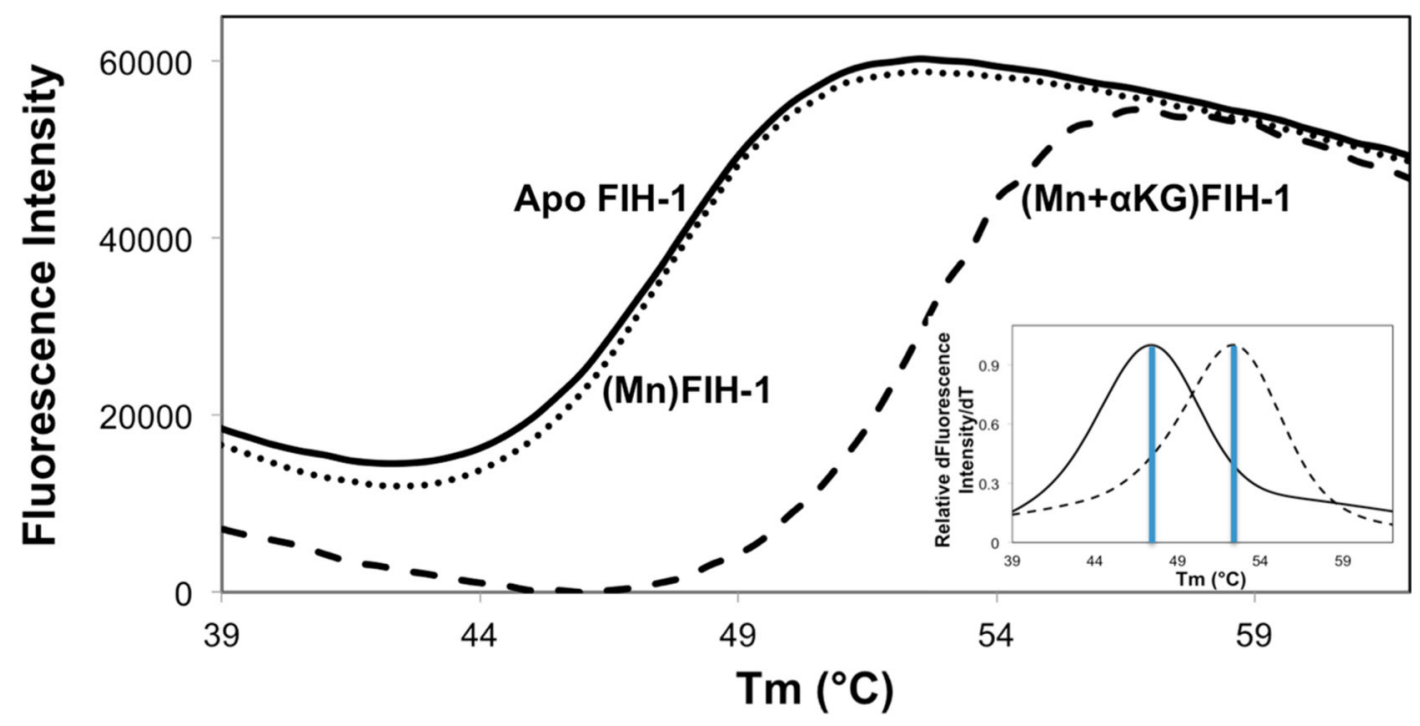

Figure 3.

Thermal shift curves showing the effect of $a \mathrm{KG}$ on the thermal stability of FIH. The inset is the derivative plot to facilitate apparent melting point determination. The thermal shift of the assay mix containing one, two, or all of the components [5 $\mu \mathrm{M} \mathrm{FIH,} 50 \mu \mathrm{M} \mathrm{MnSO}_{4}$, and 500 $\mu \mathrm{M} a \mathrm{KG}$ in $50 \mathrm{mM}$ HEPES (pH 7.0)] was monitored using SYPRO Orange dye using a thermocycler. 


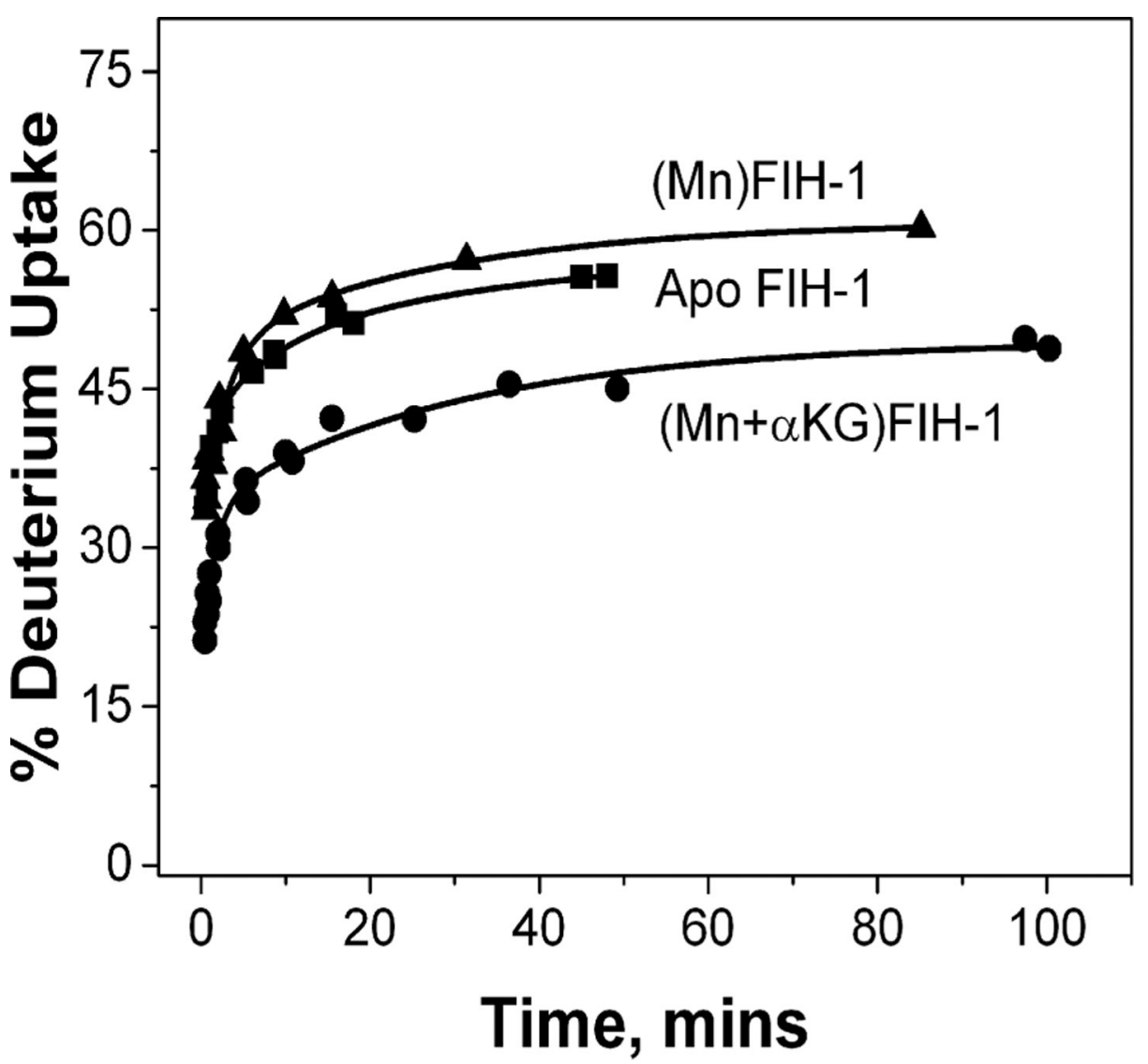

Figure 4.

Global deuterium uptake plots showing the effect of $a \mathrm{KG}$ on the backbone amide solvent accessibility of FIH. H/D exchange was initiated by diluting samples in $10 \mathrm{mM}$ ammonium acetate buffer (pD 7.4) to give final concentrations of $20 \mu \mathrm{M} \mathrm{FIH,} 50 \mu \mathrm{M} \mathrm{MnSO}{ }_{4}$, and 500 $\mu \mathrm{M} a \mathrm{KG}$. 

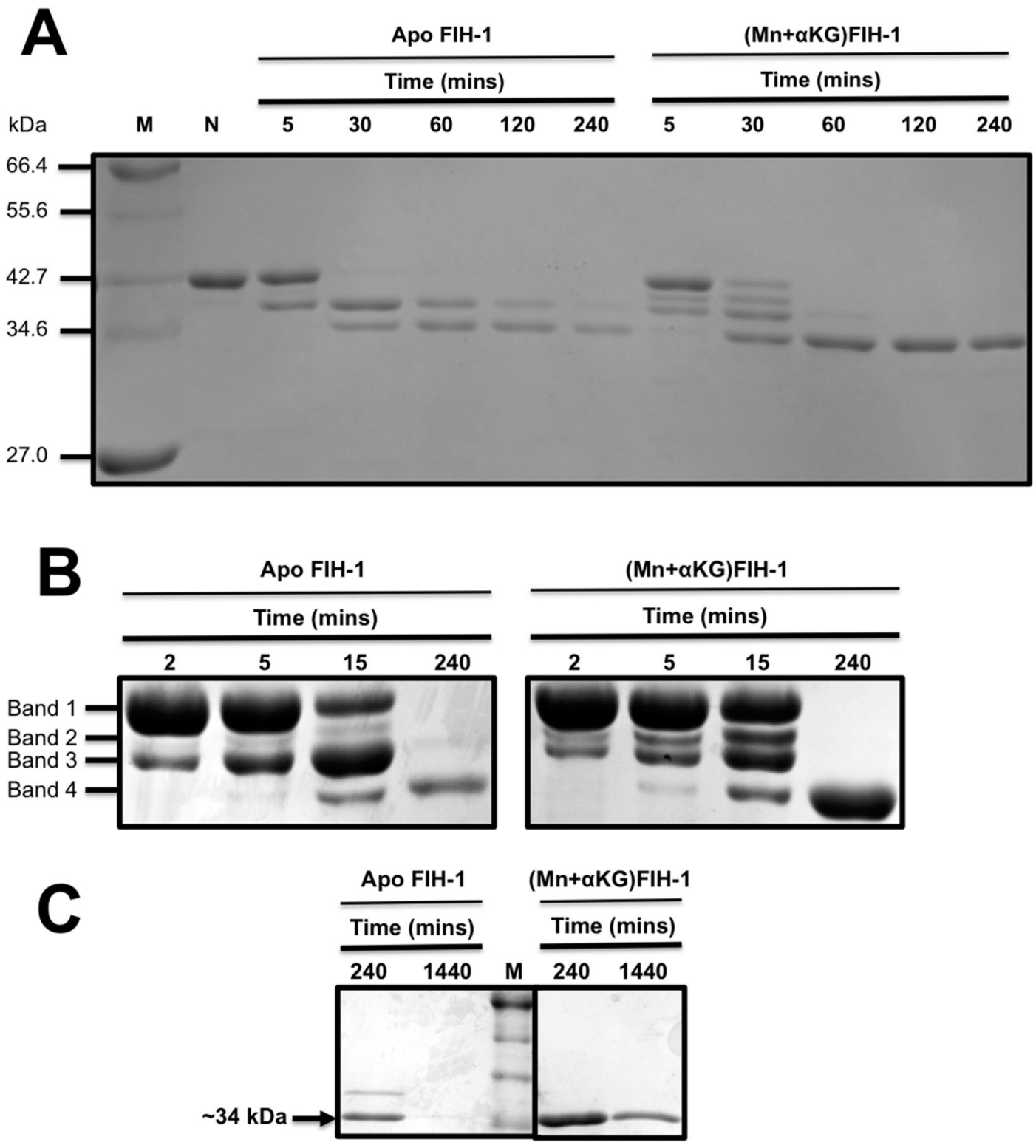

Figure 5.

Limited proteolysis of FIH in the absence and presence of $a \mathrm{KG}$ as analyzed via SDSPAGE. $\mathrm{N}$ indicates the negative control, $(\mathrm{Mn}+a \mathrm{KG}) \mathrm{FIH}$ without trypsin incubated for $4 \mathrm{~h}$ (240 min) at $37^{\circ} \mathrm{C} ; \mathrm{M}$ is the molecular weight marker. Samples were analyzed in a $12 \%$ polyacrylamide gel. (A) Protein samples [150 $\mu \mathrm{g}$ of FIH, $100 \mu \mathrm{M} \mathrm{MnSO}_{4}$, and $500 \mu \mathrm{M} a \mathrm{KG}$ in $50 \mathrm{mM}$ Tris ( $\mathrm{pH} 7.5$ )] were incubated with $0.5 \mathrm{mg} / \mathrm{mL}$ trypsin in a $1: 300$ protease:substrate ratio for the indicated time points at $37{ }^{\circ} \mathrm{C}$ and then quenched in $1 \mathrm{mM}$ AEBSF. The sample loading volume was $1 \mu \mathrm{L}$ per well corresponding to $\sim 2 \mu \mathrm{g}$ of protein. (B) A second replicate sample was performed as in panel A, but the sample loading volume used this time was $3 \mu \mathrm{L}$ to make band 2 more visible. (C) A third replicate sample was prepared as in panel A, but the incubation time was extended to $24 \mathrm{~h}$. The arrow indicates the $\sim 34 \mathrm{kDa}$ fragment assigned as band 4 . 

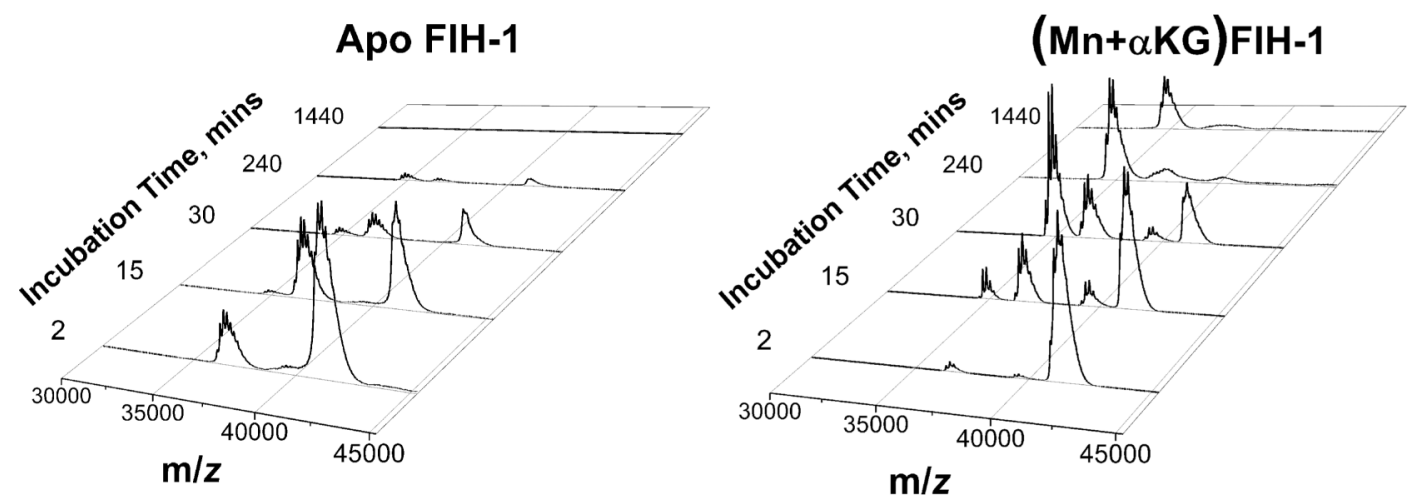

Figure 6.

Analysis of the limited proteolysis data of FIH by MALDI-TOF mass spectrometry in linear mode. The same quenched samples [150 $\mu \mathrm{g}$ of $\mathrm{FIH}, 100 \mu \mathrm{M} \mathrm{MnSO}$, and $500 \mu \mathrm{M} a \mathrm{KG}$ in $50 \mathrm{mM}$ Tris (pH 7.5)] used in SDS-PAGE analysis were mixed with $10 \mathrm{mg} / \mathrm{mL}$ sinapinic acid in $70 \% \mathrm{CH}_{3} \mathrm{CN} / 0.03 \%$ TFA in a 1:5 sample:matrix ratio. 
MAATAAEAVA SGSGEPREEA GALGPAWDES QLRSYSFPTR PIPRLSQSDP RAEELIENEE 60

Figure 7.

Primary structure of FIH showing all of the possible trypsin cleavage sites colored red.

Highlighted in gray are the amino acids involved in the FIH dimer interface. The expressed protein used has three additional residues (GSH-) at the N-terminus, which are not included in the figure. 

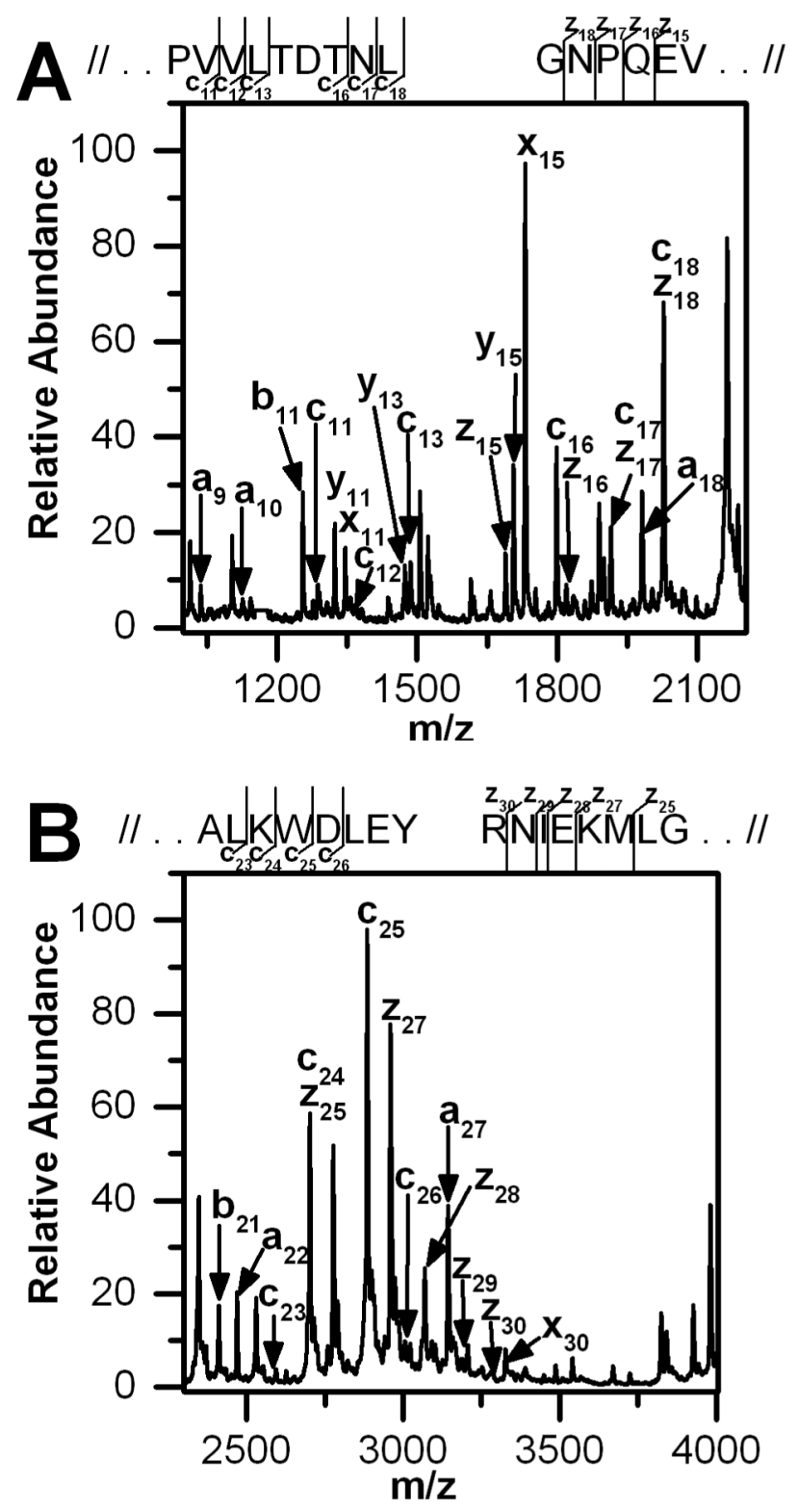

Figure 8.

Top-down sequence verification of the $\sim 34 \mathrm{kDa}$ tryptic fragment (band 4 ) of FIH using ISD coupled to MALDI-TOF MS. The sample quenched after protease incubation for $4 \mathrm{~h}$ was used for the analysis. It was mixed with $10 \mathrm{mg} / \mathrm{mL}$ sinapinic acid in $30 \% \mathrm{CH}_{3} \mathrm{CN} / 0.1 \%$ TFA in a 1:1 ratio. (A) Spectrum showing the $c, z_{n}+2$, and a few y ions identified for the $\mathrm{m} / z$ range of $<2000$. Also shown are the verified $\mathrm{N}$ - and C-terminal sequences of FIH. (B) Spectrum for the $m / z$ range of $>2000$. 


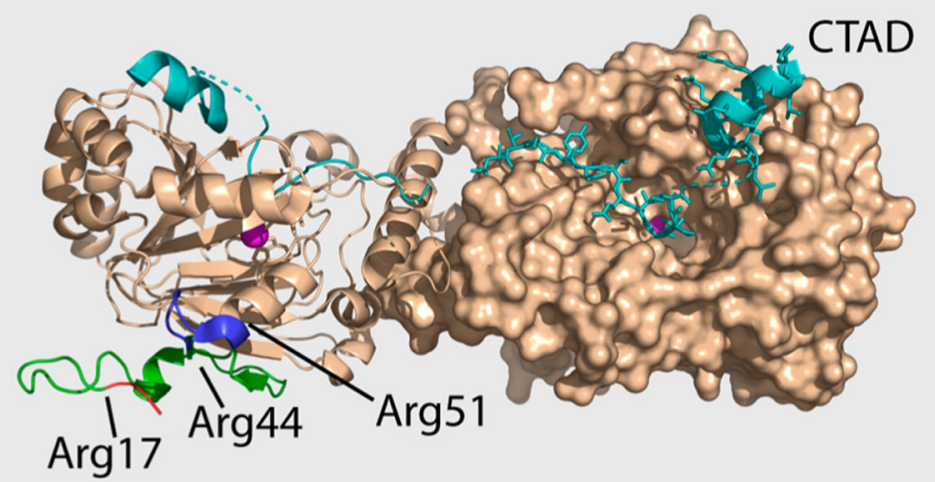

Figure 9.

Biological dimer of FIH (PDB entry 1H2K), showing CTAD (cyan) and the trypsin fragments of FIH: N-terminus-Arg17 (red), Glu18-Arg44 (green), Leu45-Arg51 (blue), and Ala52-Asn349 (wheat). 


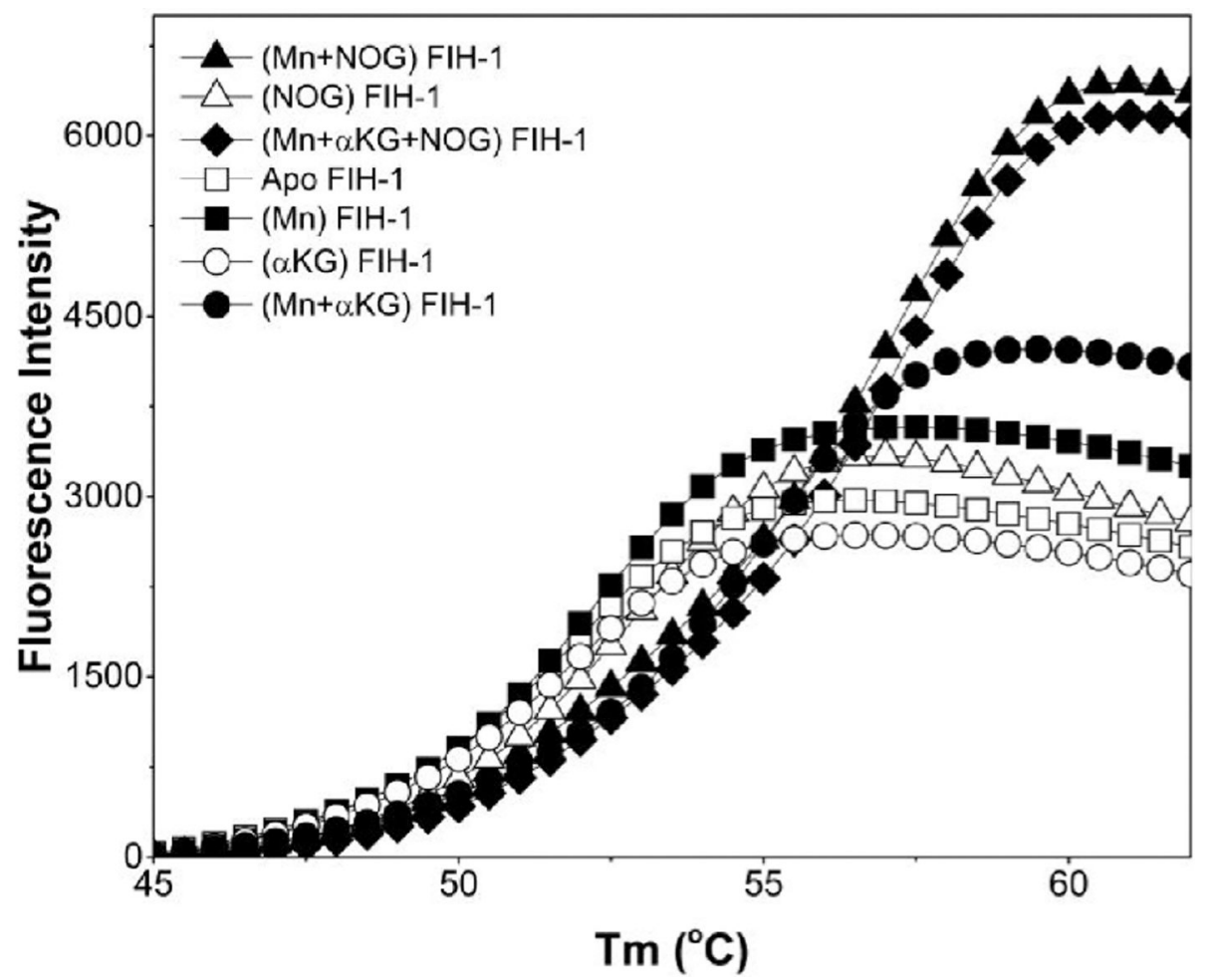

Figure 10.

Thermal shift assay for ligand binding to FIH. Assays were conducted using $5 \mu \mathrm{M}$ WT FIH, $5 \mu \mathrm{M} \mathrm{MnSO}_{4}, 200 \mu \mathrm{M}$ NOG or $100 \mu \mathrm{M} a \mathrm{KG}$, and $5 \times$ SYPRO Orange dye in $50 \mathrm{mM}$ HEPES (pH 7.00). 


\section{Table 1.}

Summary of Global HDX Data

\begin{tabular}{|c|c|c|c|}
\hline & $\operatorname{apoFIH}^{a}$ & $(\mathrm{Mn}) \mathrm{FIH}^{a}$ & $(\mathrm{Mn}+a \mathrm{KG}) \mathrm{FIH}^{a}$ \\
\hline$y_{0}$ & $186 \pm 1$ & $199 \pm 5$ & $157 \pm 2$ \\
\hline$A_{\text {slow }}$ & $47 \pm 2$ & $60 \pm 8$ & $55 \pm 4$ \\
\hline$B_{\text {medium }}$ & $55 \pm 3$ & $50 \pm 11$ & $51 \pm 6$ \\
\hline$C_{\text {fast }}$ & $84 \pm 3$ & $89 \pm 10$ & $51 \pm 6$ \\
\hline
\end{tabular}

${ }^{a}$ The corresponding average rate constants were fixed accordingly during the fitting: $k_{1}\left(0.05 \mathrm{~min}^{-1}\right), k_{2}\left(1 \mathrm{~min}^{-1}\right)$, and $k_{3}\left(20 \mathrm{~min}^{-1}\right) .36$

The initial parameters obtained were relative values; the number of exchangeable amides reported above was calculated by multiplying the relative values by $N(N=324)$. The HDX experiments were performed in duplicate. 
Table 2.

Summary of the Average Observed Masses for the Four Major Tryptic Fragments Determined after MALDITOF MS Analysis

\begin{tabular}{lccl}
\hline \multicolumn{1}{c}{ protein species } & observed MW $^{\boldsymbol{a}}$ & calculated MW & fragment $^{\boldsymbol{c}}$ \\
band 1 (intact FIH) & $41186 \pm 635$ & 40567 & -3 to 349 \\
band 2 & $39601 \pm 489$ & 38728 & $18-349$ \\
band 3 & $36654 \pm 585$ & 35714 & $45-349$ \\
band 4 & $34904 \pm 609$ & 34931 & $52-349$ \\
\hline
\end{tabular}

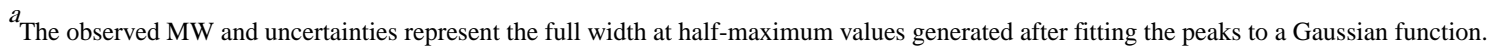

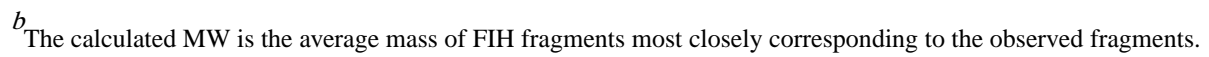

$c_{\text {The processed FIH as used contains a leading sequence Gly-Ser-His-. }}$
} 
Table 3.

Summary of the Observed $c$ and $z$ Ions for the $34 \mathrm{kDa}$ Fragment (band 4) Generated during ISD-MALDI-TOF $\mathrm{MS}^{a}$

N-terminus: AEELIENEEPVVLTDTNLVYPALKWDLEYLQE

\section{C-terminus: MRNIEKMLGEALGNPQEVGPLLNTMIKGRYN}

\begin{tabular}{crcccc} 
sequence (N-terminus) & observed $(\boldsymbol{c}$ ions $)$ & calculated $(\boldsymbol{c}$ ions $)$ & sequence (C-terminus) & observed $(z$ ions $)$ & calculated $(z$ ions $)$ \\
V & 1270 & 1271 & G & 2028 & 2028 \\
V & 1369 & 1370 & N & 1915 & 1915 \\
L & 1484 & 1483 & P & 1819 & 1818 \\
T & - & 1584 & Q & 1689 & 1689 \\
D & - & 1699 & E & - & 1560 \\
T & 1799 & 1800 & V & 1461 & 1461 \\
N & 1915 & 1914 & G & - & 1404 \\
L & 2028 & 2027 & P & 1308 & 1307 \\
K & 2699 & 2698 & N & 3186 & 3185 \\
W & 2885 & 2884 & I & 3070 & 3071 \\
D & 3001 & 3000 & E & 2959 & 2958 \\
L & - & 3113 & K & - & 2828 \\
E & 3242 & 3242 & M & 2701 & 2700 \\
\hline
\end{tabular}

${ }^{a}$ The regions of the $\mathrm{N}$ - and C-termini identified from sequence analysis are highlighted in gray. 